\title{
Migración indocumentada cubana por Centroamérica: El papel de Nicaragua en la crisis migratoria de 2015
}

\section{Cuban undocumented through Central America: The role of Nicaragua in the migration crisis of 2015}

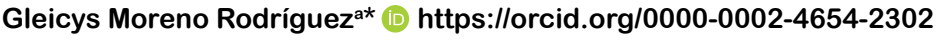

a Centro de Investigación en Ciencias de Información Geoespacial (CentroGeo), Ciudad de México, México, correo electrónico: gleicys.moreno@gmail.com

\section{Resumen:}

El objetivo del artículo es analizar el papel de Nicaragua en la crisis de migrantes cubanos indocumentados ocurrida a finales de 2015 en Centroamérica. El periodo de estudio comienza en el mes de noviembre de 2015 con el cierre de la frontera nicaragüense y culmina en febrero de 2016, tras lograrse un acuerdo entre la mayoría de las naciones implicadas. Para estudiar lo anterior, se realizó una búsqueda de información en varios medios de prensa, se consultaron las declaraciones oficiales emitidas por las autoridades cubanas y sandinistas, y se entrevistó a migrantes, diplomáticos y expertos en el tema. La investigación constituye un acercamiento a un fenómeno que reconfiguró las relaciones migratorias entre Cuba y Estados Unidos.

Palabras clave: Cuba, Estados Unidos, Nicaragua, migración, crisis.

*Autor para correspondencia: Gleicys Moreno Rodríguez, correo electrónico, gleicys.moreno@gmail.com

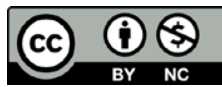

Esta obra está protegida bajo una Licencia Creative Commons Atribución-NoComercial 4.0 Internacional.

\section{Abstract:}

The objective of this article is to analyze the role of Nicaragua in the crisis of Cuban migrants that occurred at the end of 2015 in Central America. The study period begins on November 2015 with the closing of the Nicaraguan border, and ends in February of 2016, with an agreement between most of the nations involved. Information was sought in media outlets, the official speeches by the Cuban and Nicaraguan authorities were consulted, and interviews were conducted with migrants, diplomats and experts. The text is an approach to a phenomenon that reconfigured relations between Cuba and the United States.

Keywords: Cuba, United States, Nicaragua, migration, crisis.

CÓMO CITAR: Moreno, G. (2019). Migración indocumentada cubana por Centroamérica: El papel de Nicaragua en la crisis migratoria de 2015. [Cuban undocumented through Central America: The role of Nicaragua in the migration crisis of 2015]. Estudios Fronterizos, 20, e038. doi:https://doi.org/10.21670/ref.1917038 


\section{Introducción y metodología}

La migración cubana hacia territorio estadunidense no constituye un fenómeno reciente en la historia internacional. Aunque en el plano de los grandes flujos migratorios, tanto a escala mundial como regional, Cuba no clasifica como un país que aporte cifras considerables de emigrantes hacia su principal receptor, Estados Unidos, la historia de enfrentamiento-acercamiento que han tenido las dos naciones desde el 1 de enero de 1959 sí ha hecho que la migración tenga características especiales, las cuales han variado dependiendo de la relación, el contexto y las prioridades de cada gobierno (Aja, citado en Moreno, 2018, p. 40). No es de extrañar, entonces, que desde el triunfo de la Revolución se hayan producido varios picos migratorios irregulares que han tenido como destino la nación norteña, entre ellos Boca de Camarioca, El Mariel y la Crisis de los Balseros de 1994, por solo mencionar algunos.

Estos éxodos han sido estudiados con detalle por numerosos especialistas en el tema, quienes se han centrado en los factores sociodemográficos, el contexto histórico en el que se produjeron y la inserción de los nuevos migrantes en el país de destino, entre otros aspectos. En este sentido podemos nombrar a Antonio Aja (2009), Nivia Marina Brismat (2011), Lorena G. Barberia (2010), Lourdes de Urrutia Barroso (1997), Yusmany Hernández (2011), Humberto López (2008), Milagros Martínez (1996) y Ernesto Rodríguez (1997).

Con base en lo anterior, el presente artículo tiene como objetivo analizar el surgimiento de la crisis de migrantes cubanos que se dio en Centroamérica, en el mes de noviembre de 2015, cuando Nicaragua cerró su frontera a los isleños que se venían desplazando por el continente con el propósito de llegar a Estados Unidos. Para explicar el surgimiento de dicha crisis se propone la siguiente hipótesis: que la misma fue planificada por Cuba con la ayuda de Daniel Ortega para presionar al gobierno estadunidense a dar pasos en el área, lo que efectivamente ocurrió en el mes de enero de 2017, cuando el entonces presidente Barack Obama eliminó la Política de Pies Secos-Pies Mojados ${ }^{1}$ y el Programa de Permisos para Profesionales Médicos Cubanos, ${ }^{2}$ un reclamo continuo del gobierno cubano a lo largo de los años.

Para el presente artículo se utilizó una metodología cualitativa, en este sentido, las técnicas de investigación se basan, esencialmente, en entrevistas en profundidad a los diplomáticos de los Estados involucrados. ${ }^{3}$ Asimismo, se consultaron los discursos y las declaraciones ofrecidas por los diversos mandatarios desde noviembre de 2015 y hasta febrero de 2016. Esto fue complementado con entrevistas semiestructuradas a migrantes que se encontraban en tránsito cuando el gobierno de Daniel Ortega decidió cerrar las fronteras, aludiendo cuestiones relativas a la soberanía del país.

\footnotetext{
${ }^{1}$ La Política de Pies Secos-Pies Mojados planteaba como principal supuesto que los cubanos que fuesen interceptados en altamar serían devueltos a Cuba; mientras que quienes lograran pisar territorio estadunidense disfrutarían de beneficios en ese país, entre ellos, el permiso de trabajo y bonos de alimentación, y al año y un día podrían aplicar a la residencia permanente según la Ley de Ajuste Cubano de 1966.

${ }^{2}$ Con este programa, el Departamento de Seguridad Nacional permitía la entrada del personal médico cubano que estuviese cumpliendo una misión del gobierno de Cuba en un tercer país y decidiera desertar de la misma. Lo anterior facilitaba el posterior ingreso del cónyuge y los hijos menores de 21 años (Departamento de Seguridad Nacional de Estados Unidos, s.f.).

${ }^{3}$ Esta constituyó una de las limitantes de la investigación, pues se hizo difícil el acceso a los funcionarios de varios países implicados en la toma de decisiones, como se tenía planificado originalmente.
} 
Se realizó una revisión exhaustiva de las notas de prensa y reportajes publicados en los principales medios impresos y digitales de Nicaragua, México, Costa Rica, Cuba, Estados Unidos y el resto de las naciones involucradas, desde el 14 de noviembre de 2015 hasta el mes de febrero de 2016. En el caso nicaragüense están La Prensa, El Nuevo Diario y El 19 Digital; mientras que en el mexicano se encuentran Reforma, El Universal, La Jornada y El Financiero. También tuvimos en cuenta la explicación ofrecida por los medios oficiales cubanos, Granma, Juventud Rebelde y Cubadebate, y los estadunidenses The New York Times, Martinoticias, The Washington Post, Los Angeles Times y El Nuevo Herald. Se consultaron, además, el diario hondureño El Heraldo, los ecuatorianos El Telégrafo y El Comercio, el panameño La Prensa y en el territorio costarricense La Nación y el canal oficial de la Casa Presidencial de Costa Rica. Por último, se revisaron los recursos bibliográficos sobre el tema y nos apoyamos en entrevistas en profundidad con expertos en migración. De ahí que las fuentes de investigación hayan sido principalmente primarias y secundarias, entre las que se pueden mencionar artículos, revistas, libros, legislaciones, periódicos y videos.

El texto está estructurado de la siguiente manera. En un primer momento se ofrecerá una breve historia del proceso migratorio cubano desde el triunfo de la Revolución y hasta el anuncio del restablecimiento de relaciones el 17 de diciembre de $2014^{4}$ (en adelante 17-D), con el propósito de entender que la migración cubana es un fenómeno histórico, estrechamente ligado a ese vaivén que ha caracterizado los vínculos entre Cuba y Estados Unidos desde 1959. Posteriormente, se analizará el contexto y las particularidades en las que ocurrió la crisis de 2015, para luego explicar el papel del gobierno nicaragüense en la creación de la misma. En el cuarto y último acápite se indicarán cuáles son las tendencias actuales de la migración cubana, tras la llegada de Donald Trump a la presidencia de Estados Unidos. La relevancia del estudio se encuentra en ser uno de los primeros acercamientos al tema de los movimientos migratorios cubanos de tránsito por el continente hacia territorio estadunidense.

\section{Antecedentes del flujo migratorio cubano}

La tradición del flujo migratorio de Cuba hacia Estados Unidos tiene sus orígenes muchos años antes del triunfo de la Revolución. Ya desde finales del siglo xix eran miles los cubanos que habitaban en la nación estadunidense, debido a los vínculos existentes entre ambos Estados. Un censo norteamericano publicado en 1958 daba cuenta de la existencia en ese país de un total de 125000 cubanos, cifra que incluía tanto a los inmigrantes como a sus descendientes. Antonio Aja (citado por Reed, 2015), por su parte, indica que en el periodo comprendido entre 1930 y 1959, los destinos más usuales para la emigración eran, además de la nación norteña, España, Venezuela y Puerto Rico.

\footnotetext{
${ }^{4}$ En esta fecha Cuba y Estados Unidos anunciaron el restablecimiento de las relaciones diplomáticas e iniciaron el proceso hacia la normalización de los vínculos bilaterales. En este sentido, el gobierno cubano indica que para que exista una verdadera normalización debe desaparecer la esencia del conflicto: hegemonía contra soberanía (Ramírez, 2016).
} 
Sin embargo, la llegada al poder de Fidel Castro Ruz, el 1 de enero de 1959, hizo que este flujo adquiriera características distintivas que lo diferenciaron del resto de las migraciones que ocurrían en el continente, debido, entre otros factores, a la política emigratoria cubana, la inmigratoria estadunidense y las condiciones internas por las que atravesó la mayor de las Antillas a partir de esa fecha.

No es de extrañar entonces que los primeros éxodos migratorios ocurrieran entre los meses finales de 1958 y comienzos de los años sesenta, cuando los allegados al régimen del entonces presidente Fulgencio Batista empezaron a abandonar el país ante la falta de identificación con los ideales de la Revolución y los postulados que la misma esgrimía. La situación fue aprovechada por la administración estadunidense que, en 1961, aprobó el Programa para Refugiados Cubanos y un año después John Fitzgerald Kennedy firmó el Acta de Asistencia a la Migración y a los Refugiados del Hemisferio Occidental.

Cuba, como respuesta a estas decisiones, decidió implementar en el mes de diciembre de 1961, la Ley 989, la cual estipulaba las condiciones de entrada y salida de los cubanos (Brismat, 2011, p. 154). Sin embargo, a pesar de la aplicación de dicha legislación, desde el mes de octubre de 1962 y hasta el 28 de septiembre de 1965 habían ingresado a Estados Unidos un total de 69000 personas (López, 2008, pp. 112-114). Por su parte, fuentes cubanas indican que durante ese periodo migraron cerca de 274000 nacionales, muchos de ellos sin ningún trámite burocrático, pues la administración estadunidense autorizó, tanto a personas como a entidades, la concesión de visas, incluidas aquellas utilizadas para casos de extrema urgencia (Hernández, 2011, p. 307).

El primer gran pico migratorio en esta época ocurrió en 1965, en Boca de Camarioca. López Morales (2008) explica que el 7 de octubre de ese año un aproximado de 5 000 personas llegaron a Florida, un mes más tarde, 3 000; mientras un total de 2014 cubanos comenzó a salir rumbo a Cayo Hueso en el mes de noviembre. Según Aja (2009, p. 108), durante la primera década de la Revolución un monto de 377562 cubanos fueron registrados como inmigrantes en Estados Unidos, cifra que duplicaba la inmigración de igual origen en ese país desde comienzos del siglo xx y hasta 1958. Con el paso del tiempo, la migración adquirió mayor fuerza con la Ley de Ajuste Cubano o Ley Pública 89-732, aprobada en noviembre de $1966^{5}$ (Martínez, 1996, p. 15).

Diez años después, Cuba puso en vigor la Ley de Migración de 1976 (Ley No 1313, 1976). Es de destacar también que en esta década comenzó a tomar un papel más importante la utilización de terceros países para llegar a Estados Unidos (Aja, 2009, pp. 108-110). Cifras consultadas señalan que entre 1973 y 1979 habían arribado a territorio estadunidense, a través de un tercer país, un aproximado de 179000 cubanos procedentes, en su mayoría, de España, México y Venezuela (López, 2008, pp. 114-116).

\footnotetext{
${ }^{5}$ Esta legislación, aprobada por el Congreso estadunidense, funciona de manera paralela a la Ley de Inmigración de Estados Unidos y posibilita que los migrantes cubanos, tanto los que arriban de manera regular como los que lo hacen de forma irregular a territorio norteamericano, puedan aspirar a la residencia permanente al año y un día de haber llegado. Su antecedente jurídico y basamento ideológico se encuentra en la Ley Walter-McCarran de 1952 (Martínez, 1996, p. 15).
} 
Otro gran éxodo migratorio ocurrió en 1980, con la apertura del puerto de El Mariel, cuando cerca de 124000 personas salieron de Cuba en un periodo de cinco meses. Este episodio juntó a las dos naciones en 1984. Entre los acuerdos alcanzados destaca el compromiso del gobierno estadunidense de otorgar a los cubanos 20000 visas al año; mientras Cuba aceptó recibir a un grupo de "marielitos" (así se conoce a quienes emigraron por El Mariel) que poseían antecedentes delictivos. Sin embargo, la cantidad de visas otorgadas de 1984 a 1994 no superó las 11222 por año (De Urrutia, 1997, pp. 52-53).

El derrumbe de la Unión Soviética, principal socio económico y comercial de Cuba, llevó a la implementación del llamado "periodo especial en tiempo de paz". La ausencia de recursos para satisfacer las necesidades básicas de la población, junto al decrecimiento del PIB en 34.8\%, en el periodo comprendido entre 1989 y 1993 (Rodríguez, 1997, p. 51), llevó a muchos cubanos a abandonar la isla utilizando balsas de factura casera. Datos de los guardafronteras estadunidenses confirman que en 1991, 1992 y 1993, las cifras ascendieron a 2 173, 2557 y 3656 personas, respectivamente (Martínez, 1996, pp. 5-6).

La llegada del año 1994 estaría marcado por la Crisis de los Balseros. Según Brismat (2011, p. 164), en menos de un mes casi 35000 personas se hicieron a la mar en embarcaciones sumamente frágiles y sin ningún conocimiento de navegación. El flujo irregular entre los dos países continuó hasta el mes de septiembre de ese año, cuando se firmó, en Nueva York, un nuevo entendimiento migratorio.

Estas negociaciones dieron como resultado: el otorgamiento de visas mediante un sorteo especial (conocido en Cuba como "el bombo"), la atención de los casos pendientes de respuesta de años anteriores, y el compromiso de Estados Unidos (al igual que en los acuerdos de 1984) de dar 20000 visas legales a los cubanos que desearan migrar, entre otros aspectos (Brismat, 2011, p. 164). Ambas partes también acordaron juntar esfuerzos para luchar contra la trata de personas y celebrar consultas de manera periódica sobre la aplicación del acuerdo (LeoGrande y Kornbluh, 2015, p. 332).

A pesar de lo anterior, el panorama interno para el presidente Clinton no parecía mejorar. En noviembre de 1994 el Partido Republicano ganó el control de la Cámara y el Senado; mientras un total de 20000 balseros cubanos interceptados durante la crisis permanecía todavía en la Base Naval de Guantánamo. Este problema llevó a los dos gobiernos a reunirse nuevamente para tratar de resolver la situación de los detenidos y evitar que situaciones parecidas volvieran a ocurrir en el futuro. De esta manera, en el mes de mayo de 1995 se firmaría la Declaración Conjunta con la República de Cuba sobre la Normalización de la Migración (LeoGrande y Kornbluh, 2015).

Los refugiados cubanos todavía podían obtener la residencia permanente bajo la Ley de Ajuste Cubano de 1966, pero sólo si lograban llegar a los Estados Unidos. Los refugiados interceptados en el mar serían devueltos a Cuba. Por esa distinción, la nueva política llegó a ser conocida como "Pie Mojado, Pie Seco" (LeoGrande y Kornbluh, 2015, p. 336).

Aja (2009, p. 172) señala que en cumplimiento de las medidas acordadas a mediados de los noventa, hasta el segundo semestre del 2000, el gobierno estadunidense había devuelto a Cuba más de 2700 personas capturadas en altamar y cerca de 390 que intentaron ingresar por la Base Naval de Guantánamo. 
Por estos años los cubanos también migraron de manera irregular hacia las islas Gran Caimán, Jamaica, Bahamas y República Dominicana. Desde 1985 y hasta los acuerdos de 1995 este tipo de fenómeno involucró a un total de 82500 personas (Aja, 2009). "Se utiliza la ruta que conduce a Centroamérica como ruta alternativa [...] Se han incrementado las salidas ilegales con destino a Honduras, directamente pasando por las Islas Caimán, para transitar la frontera de México con Estados Unidos" (Martín, citado en Aja, 2009, p. 11).

Datos de un censo norteamericano indican que desde 1960 y hasta 2005 había un total de 946716 residentes en Estados Unidos que habían nacido en Cuba; mientras para 2010 la cifra sobrepasaba el millón de habitantes (Reed, 2015). Entre tanto, el Centro de Estudios de Migraciones Internacionales de la Universidad de La Habana y el Censo de la Dirección de Atención a Cubanos en el Exterior, del Ministerio de Relaciones Exteriores de Cuba (MINREX), recogían que hasta el año 2002 unos 130000 cubanos habitaban en América Latina, 37000 en Europa y más de 1000 en el resto del mundo. En la Tabla 1 se puede observar la cantidad de cubanos que residían en el exterior desde 2008 y hasta 2012 y desde 2013, fecha en la que entró en vigor la nueva Ley de Migración Cubana, hasta 2016.

Tabla 1: Cantidad de cubanos que residen en el exterior de 2008 a 2016

\begin{tabular}{|c|c|c|c|}
\hline & Total & De 2008 a 2012 & De 2013 a 2016 \\
\hline Total del país & 238524 & 97811 & 140713 \\
\hline De forma temporal & 55424 & 8619 & 46805 \\
\hline De forma permanente & 183100 & 89192 & 93908 \\
\hline
\end{tabular}

Nota. Se encontraron 1518 respuestas de desconocimiento o rechazo para $0.6 \%$.

Fuente: Base de datos de la ENMIg 2016-2017 (ONEI-CEPDE, 2016).

Aja (2002, pp. 16-17) agrega que la diversificación de los destinos es un ejemplo de la tradición en el flujo migratorio hacia esos lugares, principalmente, Venezuela, México y España, junto a la presencia de las redes de parentesco. "Todo lo anterior se encuentra vinculado de manera estrecha a la utilización de países puentes y las posibilidades reales encontradas por los migrantes para su traslado hacia la nación estadounidense" (Moreno, 2018, p. 57). En este sentido, podemos ver en la Figura 1 la cantidad de cubanos detenidos en estaciones migratorias mexicanas desde 2001 hasta 2014.

Con la llegada de George W. Bush a la presidencia se pusieron en práctica dos programas que continuaron incentivando el flujo migratorio proveniente de Cuba. El primero fue el Programa de Permisos para Profesionales Médicos Cubanos, en vigor desde 2006, y el segundo, que aún continúa vigente, es el Programa de Permiso de Reunificación Familiar Cubano (CFrP). ${ }^{6}$ En este sentido, Aja destaca

${ }^{6}$ Este programa posibilita que los ciudadanos estadunidenses y los residentes legales pidan la entrada a Estados Unidos de los familiares que viven en Cuba. Los beneficiarios pueden solicitar permiso de empleo mientras solicitan la residencia permanente legal (Departamento de Seguridad Nacional de Estados Unidos, s.f.). 
(2010, pp. 116-117) que desde 1995 y hasta 2008, la cifra de visas otorgadas por la Sección de Intereses de Estados Unidos en La Habana no excedió las 190000.

Figura 1: Número de cubanos asegurados en estaciones migratorias de México, 2001-2014

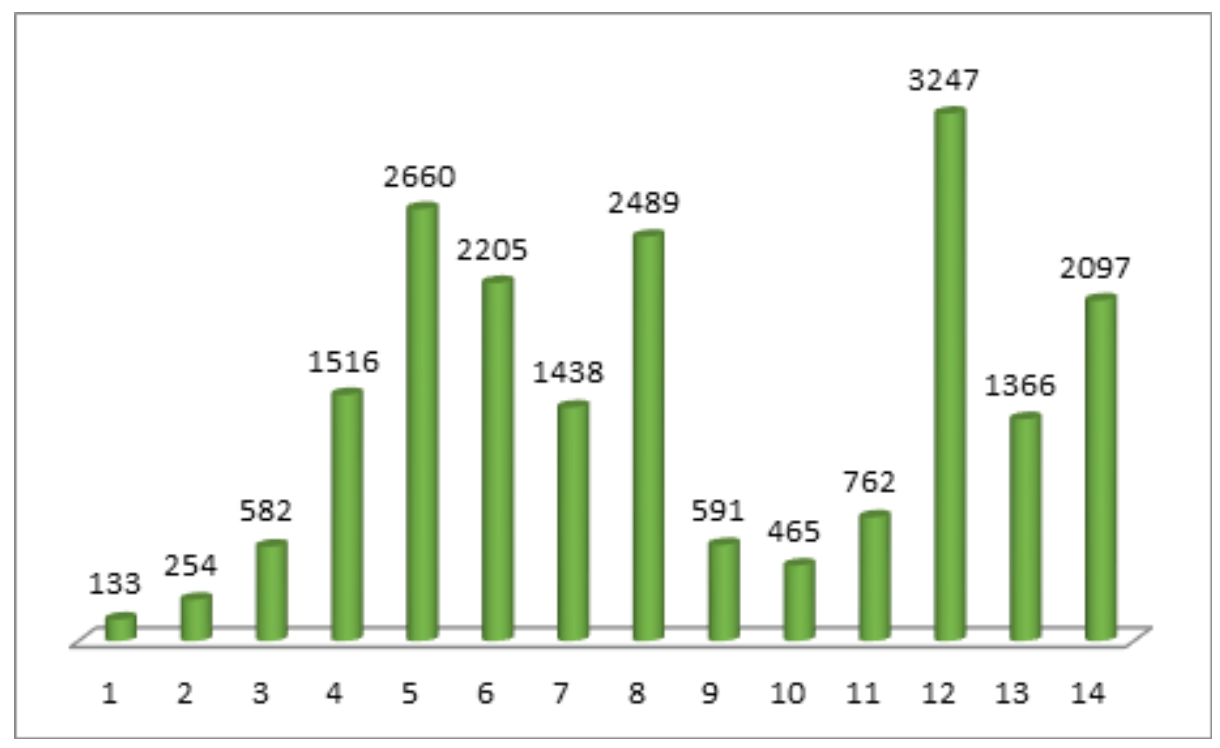

Fuente: Elaboración propia a partir de Boletines estadísticos (Secretaría de Gobernación, 2018).

La emigración cubana fue reforzada en el siglo xxi con la aplicación, en 2013, del Decreto-Ley Número 302, modificativo de la Ley Número 1312, "Ley de Migración”, de septiembre de 1976 (Decreto-Ley Número 302, 2012). Las disposiciones contenidas en la legislación flexibilizaron los requisitos para la salida de cubanos del país y el tiempo de estancia de los mismos en el exterior.

Según Brismat (2011, pp. 155-156), la existencia de leyes que amparan al migrante cubano, junto a la falta de procedimientos congruentes que permitan su llegada a Estados Unidos de forma legal y ordenada, ha facilitado el surgimiento de "cuellos de botella" migratorios y el desarrollo de la migración irregular como vía para llegar a la nación estadunidense. Esta válvula se ha convertido en un mecanismo del Estado cubano para controlar la migración, pues aunque el gobierno pierde hasta cierto grado el control sobre los flujos, regula la emigración promovida por los beneficios que otorga la nación norteña.

Las leyes estadunidenses, además de ser una fuente de atracción para muchos cubanos que desean migrar, atentan contra el bono demográfico cubano y su capacidad multiplicativa, pues la mayoría de las personas que abandonan el país se encuentran en edad reproductiva.

Nosotros perdemos anualmente alrededor de 38000 efectivos de población, todos muy jóvenes, con una feminización muy alta, es decir mujeres en plena capacidad reproductiva [...] En un contexto demográfico como el cubano este es un elemento disfuncional, que no ayuda a ese desarrollo, porque se pierde población joven, en plena capacidad reproductiva, productiva y necesaria demográficamente hablando (Aja, citado en Céspedes y Fariñas, 2015). 
Datos del Anuario Estadístico de Salud de Cuba 2017 (Ministerio de Salud Pública, 2018, p. 23) indican que la tasa global de fecundidad ${ }^{7}$ en la isla en la actualidad es de 0.77; mientras que el promedio de adulto mayor en relación con la población total ha ascendido de $12.9 \%$ en el año 2000 a $20.1 \%$ en 2017 . El envejecimiento de la población debido a la migración constituye también un problema para las políticas que intente establecer el Estado tanto a mediano como a largo plazo: en unos años habrá muchos más cubanos pertenecientes a la tercera edad que mano de obra activa.

\section{Cubanos en tránsito por Centroamérica: La crisis migratoria de 2015}

La migración terrestre cubana utilizando un país de tránsito ${ }^{8}$ no es un fenómeno nuevo ni posterior al 17-D; sin embargo, datos consultados evidencian un aumento considerable de la misma, tras el anuncio del restablecimiento de relaciones entre Cuba y Estados Unidos. Mientras en el segundo lustro del presente siglo las cifras de migrantes que llegaban a esa nación de manera irregular no sobrepasaban las 15 000 personas, en 2014 se contabilizaron cerca de 25 000, y para 2015, 43159 cubanos habían arribado de esa manera a territorio estadunidense, contando tanto las llegadas marítimas como las terrestres (Miroff, 2015).

El sitio web Martí Noticias, por su parte, detalla que desde octubre de 2014 y hasta septiembre de 2015, 43159 cubanos ingresaron a Estados Unidos; mientras en el periodo anterior solamente lo hicieron 24278 personas (De Armas, 2015). Según Aja (2017), en los tres primeros meses de 2015, la llegada de cubanos a territorio estadunidense también duplicó la cifra de la etapa previa, aunque el pico más alto se produjo en el último trimestre de ese año, cuando más de 16000 personas alcanzaron la frontera.

Una de las rutas utilizadas por aquellos que decidían migrar a través de un tercer país, aunque no la única, era un viaje en avión hasta Ecuador, ${ }^{9}$ debido a las facilidades de ingreso que empezó a ofrecer ese país desde 2008. ${ }^{10}$ Una vez en ese territorio, los migrantes cruzaban la frontera hacia Colombia donde pagaban una visa de tránsito por 300 dólares o sobornaban a los policías con la ayuda de los "coyotes" que se encontraban en el camino, según testimonios de quienes emprendieron ese recorrido. De ahí se dirigían a Puerto Obaldía, perteneciente a la comarca panameña

\footnotetext{
${ }^{7}$ La tasa global de fecundidad se entiende como el número de hijos promedio que tendría cada miembro de una cohorte hipotética de mujeres que durante el periodo fértil tuvieran sus hijos de acuerdo con las tasas de fecundidad por edad de la población en estudio y no estuvieran expuestas al riesgo de la mortalidad antes del término del periodo fértil (ONEI, 2017).

${ }^{8}$ Según la Organización Internacional para las Migraciones (OIM, 2006, p. 50), un país de tránsito es aquel a través del cual pasa la persona o el grupo migratorio hacia su destino.

${ }^{9}$ Debido a los costes y la duración del viaje, la utilización de Ecuador fue una de las tantas estrategias migratorias utilizadas para llegar a Estados Unidos. Los cubanos también optaron por trasladarse a países más cercanos geográficamente y con tradición en el flujo migratorio.

${ }^{10}$ A partir de 2008, el gobierno de Ecuador estableció el principio de ciudadanía universal a través de la política de Puertas Abiertas (Flor, 2015), la cual posibilitaba que los nacionales de varios Estados, entre ellos los cubanos, ingresaran a ese territorio sin necesidad de pedir visa y, posteriormente, en 2014, sin el requisito de la carta de invitación.
} 
de Guna Yala, en lanchas con un precio de 600 dólares y, posteriormente, cruzaban una montaña. Para salir de esa localidad hacia Ciudad de Panamá, los cubanos tenían dos opciones: utilizar un barco o una avioneta, esta última con un costo de 300 dólares. ${ }^{11}$ El recorrido por Panamá y Costa Rica se hacía a bordo de autobuses (Luis Yoel Lamorú, 2017).

La directora de Migración y Extranjería costarricense, Kathya Rodríguez (citada en Bravo, 2015a), indicó que los cubanos que se presentaban al puesto de migración recibían una orden de "deportación" hacia el Estado nicaragüense, país con el cual tenían establecido ese tipo de solución, y no hacia Cuba, debido a la ausencia de convenios con la isla en esa área. "Lo único que Nicaragua pedía era el pase de una manera legal y entonces nosotros lo hacíamos bajo la figura de la deportación" (Rodríguez, citada en Bravo, 2015a). Al ingresar a su siguiente destino, los cubanos pagaban una visa de tránsito por 80 dólares, y eran enviados hacia Honduras mediante el mismo instrumento jurídico utilizado por sus antecesores: la "deportación”. Después, continuaban el viaje por Guatemala hasta entrar a México por la frontera sur.

De acuerdo con la Ley de Migración mexicana de 2011, tras la presentación o detención de un ciudadano cubano, el Instituto Nacional de Migración (INM) en México tiene un plazo determinado para resolver la situación del mismo. En ese tiempo, el INM informa a la legación de Cuba en México sobre la persona, la representación diplomática reenvía los datos a la Dirección Nacional de Migración cubana, la cual desde La Habana manda la autorización para que ese migrante sea repatriado (Ernesto Rodríguez, 2017). Aunque el vicecónsul cubano Abel Cubillas (2017) indicó que esta consulta se realiza tras haber recibido el oficio migratorio, lo cierto es que el consulado no responde la solicitud o tarda mucho, por lo que que el ing le expide a estos ciudadanos un oficio de salida por 20 días para abandonar el territorio por cualquiera de sus fronteras, independientemente del punto de internación a México ${ }^{12}$ (Ernesto Rodríguez, 2017).

Los cubanos utilizaban ese tiempo para llegar a Estados Unidos, donde al identificarse como ciudadanos de Cuba se acogían a la Política de Pies Secos-Pies Mojados y al año y un día a la Ley de Ajuste Cubano. Esta manera de migrar era conocida entre los expertos como "ruta del sur".

La dinámica de tránsito cambió ${ }^{13}$ el 10 de noviembre de 2015, cuando las autoridades costarricenses desmantelaron una red de tráfico de personas, dejando a un total de 1917 cubanos a la deriva, quienes intentaron llegar por sus medios a Nicaragua. Aunque las autoridades sandinistas habían permitido el paso de unos cientos de cubanos unas horas antes, decidieron regresar al nuevo grupo hacia Costa

\footnotetext{
11 Según la Oficina Nacional de Estadísticas, el salario promedio general en Cuba en 2015 era de 687 pesos cubanos CUP, un equivalente aproximado a 27 dólares mensuales (ONEI, 2016). Para sufragar los costos del viaje, los cubanos habían vendido sus propiedades en la isla o contaban con remesas enviadas del exterior, fundamentalmente de Estados Unidos.

12 Según Ernesto Rodríguez (2017), hasta antes de 2008 eran muy pocos los cubanos devueltos a la isla, y en la mayoría de los casos, debido a peticiones específicas del gobierno cubano. Con la firma del Memorando de entendimiento en 2008, se empezaron a permitir las deportaciones, aunque con algunos requisitos (Memorando de entendimiento, 2008). La entrada en vigor de la Ley de Migración de México en 2011 influyó al acortar el tiempo de estancia de los asegurados en las estaciones migratorias (Ley de Migración, 2011). Por su parte, el memorando de 2015 no cambió mucho lo estipulado por su antecesor.

${ }^{13} \mathrm{~A}$ pesar del cierre y la militarización de la frontera nicaragüense, algunos migrantes cubanos recurrieron a los "coyotes" para internarse al país por las zonas montañosas (Luis Yoel Lamorú, 2017).
} 
Rica. Para impedir el avance, Daniel Ortega, quien posee una estrecha relación con el gobierno cubano desde finales de la década de los setenta, ordenó militarizar la frontera y utilizar gases lacrimógenos y balas de goma contra quienes intentaran pasar (Villareal y Silva, 2015).

Ante el creciente número de cubanos que llegaban a territorio costarricense provenientes del sur -8000 en Costa Rica y 1000 en Panamá-, la situación fue llevada para su solución al Sistema de Integración Centroamericana (sica). ${ }^{14} \mathrm{La}$ imposibilidad de llegar a un acuerdo durante las primeras citas hizo que el gobierno de Luis Guillermo Solís rompiera parcialmente sus relaciones con el ente regional. Después de varios meses y algunas reuniones, y tras la negativa inicial de Guatemala y Belice, se decidió, en febrero de 2016, crear un puente humanitario para trasladar a los cubanos, primero vía aérea hacia Guatemala y, posteriormente, hasta la frontera norte mexicana, donde los cubanos se acogieron a la Política de Pies Secos-Pies Mojados.

Justo un año después de esa crisis, el presidente de Estados Unidos Barack Obama derogó, en enero de 2017, la Política de Pies Secos-Pies Mojados y el Programa de Permisos para Profesionales Médicos Cubanos. La eliminación de ambas políticas había sido una petición reiterada de Cuba a lo largo de los años, pues a juicio del gobierno constituían, junto con la Ley de Ajuste Cubano, un estímulo para la migración indocumentada. "No podemos olvidar que somos el único país del planeta a cuyos ciudadanos se les permite asentarse y trabajar en el territorio de los Estados Unidos sin visa alguna" (Castro, citado en "Por la voluntad común de la nación", 2012).

Para entender las particularidades de esta situación es necesario comenzar estableciendo las diferencias que presenta este flujo en relación con los éxodos migratorios anteriores: Boca de Camarioca, el Mariel y la Crisis de los Balseros. Según Ernesto Rodríguez (2017), mientras las dos primeras se dieron como parte de un conflicto bilateral, esta última ocurrió posterior al anuncio del restablecimiento de relaciones entre los dos países. Asimismo, a diferencia de las anteriores, la crisis de 2015 no ocurre de manera directa entre la nación de origen y la de destino, sino en un espacio regional diferente que va a involucrar a Centroamérica y a algunos países de Sudamérica.

En el caso de la corriente migratoria cubana, aunque transita de manera irregular por gran parte de los territorios, comenzó siendo un flujo regular, pues la mayoría de las personas que hicieron este recorrido salieron de Cuba de acuerdo con la Ley de Migración y entraron a los países de recepción —ya sea Ecuador, Venezuela o Guyana- según los requerimientos migratorios de cada Estado (MINREx, 2015). Por último, la situación ocurrida en Centroamérica conjuga tanto a personas que utilizaron a estos países como una vía para llegar a territorio estadunidense, como a cubanos que llevaban tiempo viviendo en ellos y tenían un proyecto de vida en esas naciones, por ejemplo México, pero que ante el temor de que fuesen eliminados los beneficios que ofrecía Estados Unidos, decidieron también emprender viaje hacia el norte, en busca del "sueño americano" (Ernesto Rodríguez, 2017).

\footnotetext{
${ }^{14}$ El SICA se constituyó el 13 de diciembre de 1991 y está integrado por Belice, Costa Rica, Nicaragua, Panamá, Honduras, El Salvador, Guatemala y República Dominicana. Su principal objetivo es convertir a Centroamérica en una región de paz, libertad, democracia y desarrollo. Para más información se puede consultar la siguiente dirección electrónica: https://www.sica.int/sica/sica_breve.aspx
} 


\section{Nicaragua y la creación de la crisis cubana}

Para analizar el surgimiento de la crisis migratoria cubana en 2015, es necesario entender por qué Nicaragua, alegando cuestiones relativas a la soberanía, decide cerrar la frontera en ese momento, cuando el flujo de migrantes cubanos vía terrestre venía aconteciendo desde hacía tiempo.

Desde el año 2012 los países de la región comprendieron mejor una nueva ruta de migración que abarcaba Centroamérica. Para esa fecha, Costa Rica detectó a 50 ingresando desde Panamá, al año siguiente, 2 500, para el 2014 fueron 5600 y este año hasta antes del conflicto (noviembre de 2015) unos 13000 (Bravo, 2015b).

Aunque la migración cubana por terceros países no es un fenómeno reciente en el tiempo, ni tuvo su origen a partir del 17-D, sí fue, a partir de esa fecha, que se comenzó a notar un incremento de la misma por la región centroamericana - ya sea aquellos que llevaban tiempo establecidos en naciones como Ecuador o Venezuela, o de quienes utilizaron alguno de los países de la región para ingresar al territorio continental-. $\mathrm{Y}$ es que, tras el anuncio del 17-D, los gobiernos cubano y estadunidense habían dado pasos importantes en el área diplomática, entre ellos, la apertura de embajadas, la visita del entonces presidente Barack Obama a Cuba y la firma de varios acuerdos en materia de comunicación, lo que hacía suponer que estos cambios continuarían. ${ }^{15}$

Asimismo, la eliminación de las políticas unilaterales que promueven la migración irregular cubana hacia territorio estadunidense había sido un reclamo del gobierno a lo largo de los años y, para esa fecha, se había convertido en una cuestión importante para lograr la normalización de los vínculos. Artículos publicados en Cuba, Nicaragua y Costa Rica aseveraban que los isleños migraban por temor a que fuese derogada la Ley de Ajuste Cubano (Bravo, 2015a). "Es posible que quienes tenían un proyecto migratorio en firme, pudieron haber apresurado una resolución ya tomada como decisión irreversible tras el anuncio del restablecimiento de relaciones diplomáticas" (Anguiano y Machado, 2015, p. 266).

Siguiendo esta línea, el diario oficial del Partido Comunista de Cuba, Granma, reconoce un aumento en el número de nacionales que emigró hacia Estados Unidos, después del 17-D. Con el objetivo de hacerle ver a la opinión pública el doble rasero de la política migratoria de Estados Unidos, el periódico cita cifras oficiales de la Oficina de Aduanas y Protección Fronteriza estadunidense que muestran que un aproximado de 27000 cubanos llegaron por la frontera de México durante los primeros nueve meses de 2015, lo que representó un incremento de $78 \%$ más que en igual periodo de 2014 (Ávila, 2015).

En este sentido, Ernesto Rodríguez (2017) asevera que solo se puede hablar de crisis migratoria cuando se evidencia un masivo incremento de personas en un plazo relativamente corto de tiempo. Al comentar sobre la situación ocurrida en noviembre de 2015 con los indocumentados cubanos, tras el cierre de la frontera nicaraguense, señala:

\footnotetext{
${ }^{15}$ En diciembre de 2015, el congresista Carlos Curbelo dio a conocer una inicativa con la cual buscaba suspender los beneficios de asistencia federal otorgados a los cubanos que acababan de ingresar a territorio estadunidense (Curbelo, 2015). Otras inciativas similares fueron presentadas por los representantes Paul Gosar, Henri Cuéllar y Blake Farenthold. En 2011, el congresista David Rivera también intentó modificar las leyes que amparaban a la migración cubana (González, 2018).
} 
Las crisis pueden tener varios orígenes y tienen que ver con el impacto que provoca en términos de intensidad, de número por unidad de tiempo y por cuestiones políticas. En el caso de la ocurrida en el 2015 tiene que ver con el incremento del flujo y con la masividad que empezó a tener. Un flujo que existía desde hace años, pero que era un goteo y después pasó a chorro y de ahí, a torrente (Ernesto Rodríguez, 2017).

La conjunción de los factores anteriormente mencionados creaba el escenario perfecto para detonar una crisis en Centroamérica que provocara una situación migratoria insostenible para los países implicados y que llevara a Estados Unidos a tomar un papel importante en su resolución. De esta manera, ambos gobiernos se verían obligados a sentarse y buscar soluciones, como había ocurrido anteriormente, debido, en esta ocasión, a las implicaciones regionales de dicha crisis.

¿Cómo crear, entonces, el escenario deseado por el gobierno cubano? La respuesta: Nicaragua. ¿Por qué? La relación entre ambos gobiernos tiene sus orígenes a finales de la década de los setenta. El 25 de julio de 1979, días después del triunfo de la Revolución sandinista, Cuba envió a Managua un avión con 90 toneladas de comida y 60 médicos y enfermeras. Antes de terminar ese año, un total de 1000 maestros, técnicos en pesca y asesores militares cubanos comenzaron a llegar al país. Durante 1980, la isla formalizó su ayuda a través de diversos acuerdos de asistencia económica, científica y técnica. Para 1983 ya se contabilizaban 4000 cubanos en Nicaragua, la mitad de ellos maestros, 750 personal médico, 1000 trabajadores de la construcción y 200 asesores militares. Asimismo, de 1979 a 1982 Cuba había donado el equivalente a 286 millones de dólares, $16.1 \%$ de la ayuda que la nación centroamericana había recibido durante ese periodo. De manera general, desde 1979 hasta 1987, la isla había enviado hacia Nicaragua un total de 64.9 millones de dólares (Domínguez, 1990, pp. 102-103). Con la llegada de Daniel Ortega al poder en 1985 y ante el incremento de las bandas contrarrevolucionarias que pretendían derrocarlo, Fidel Castro envió a asesores militares para ayudar al régimen y contribuir con su entrenamiento.

Bajo el segundo mandato presidencial de Ortega, a partir de 2007, se han firmado múltiples convenios en áreas como la educación y la salud —por ejemplo, la Operación Milagro y Yo, sí puedo-,${ }^{16}$ por lo que muchos nicaragüenses han sido atendidos por médicos cubanos o han viajado a la isla para estudiar o someterse a operaciones médicas. En este sentido, la vicepresidenta de Nicaragua, Rosario Murillo, confirmó que desde 2007 hasta el mes de octubre de 2018, 260000 nacionales se habían operado de la vista como parte de la Operación Milagro ("Compañera Rosario Murillo en Multinoticias", 2018); mientras, hasta el mes de agosto de 2018, 180000 nicaragüenses, pertenecientes a las zonas más intrincadas del país, habían sido alfabetizados con el método cubano Yo, sí puedo ("Homenaje del gobierno de Nicaragua", 2018).

Actualmente, el gobierno sandinista es el principal aliado cubano en la región, también es miembro de la Alianza Bolivariana para los Pueblos de Nuestra América (ALBA), y ha mantenido a lo largo de los años posiciones similares a las cubanas en temas importantes para la isla, entre ellos, la eliminación del embargo económico, comercial y financiero impuesto por Estados Unidos, la liberación de los cinco espías

\footnotetext{
${ }^{16} \mathrm{La}$ Operación Milagro es un plan sanitario realizado de forma conjunta entre los gobiernos de Cuba y Venezuela con el objetivo de que personas de bajos recursos de diversas naciones puedan ser operadas de la vista. Por su parte, Yo, sí puedo es un programa de alfabetización sugerido por el entonces presidente de los Consejos de Estado y de Ministros, Fidel Castro Ruz.
} 
cubanos presos en cárceles estadunidenses y el rechazo a la Ley de Ajuste Cubano y la Política de Pies Secos-Pies Mojados, entre otros. Según el abogado experto en migración Eduardo Matías (citado en Brandoli, 2015), los cubanos pidieron ayuda al gobierno sandinista tras las presiones de Estados Unidos para detener la llegada de migrantes a su territorio.

De esta manera, Nicaragua se convertía en el detonante de la crisis migratoria, la cual, debido a su duración por la negativa sandinista de encontrarle una solución, sirvió para crear una situación insostenible para los gobiernos de la región, en términos de capacidades económicas e institucionales, lo que llevó a los países pertenecientes al área a pronunciarse por la derogación de las ventajas que beneficiaban a los cubanos. Lo anterior se vio reforzado por el conflicto limítrofe que durante años han tenido Costa Rica y Nicaragua por el dragado del Río San Juan y la soberanía de Isla Portillos, caso llevado a la Corte Internacional de la Haya para su solución, y que falló a favor del gobierno costarricense el 15 de diciembre de 2015, un mes después de haber comenzado la crisis de cubanos. Este hecho contribuyó a que el tema de los migrantes tuviera un mayor posicionamiento en los medios de comunicación internacionales.

Durante el transcurso de la crisis y como parte de las reuniones que acontecieron en el sicA, los gobiernos de la región se pronunciaron por la eliminación de las políticas estadunidenses que promovían la migración de cubanos o, en su defecto, la ampliación de estas al resto de los centroamericanos. Con este fin le escribieron, incluso, al secretario de Estado estadunidense John Kerry. Cuando los países involucrados realizaron estos pronunciamientos, era obvio que la segunda opción no iba a ocurrir. Estados Unidos no iba a ampliar las facilidades dadas a los cubanos al resto de los migrantes, pues atentaría contra su propia política de seguridad nacional. Un anuncio de esa envergadura provocaría, en pocas horas, que miles de ciudadanos de diversas nacionalidades llegaran a los puestos fronterizos norteamericanos con el objetivo de acogerse a dichas leyes.

De este modo, cuando los Estados de la región hicieron esa petición no pretendían que los latinoamericanos fueran homologados a los cubanos, sino que estos últimos no tuvieran ningún beneficio, como efectivamente ocurrió el 12 de enero de 2017. Es necesario señalar que el primer país que comenzó a exigir la derogación de estas medidas fue Nicaragua, siguiendo órdenes de La Habana. Así lo demuestra el comunicado emitido por Daniel Ortega a través de su representación en una de las citas del SicA, donde exige la suspensión de las leyes que favorecían a los cubanos al pisar suelo estadunidense:

El Gobierno de Nicaragua demanda, por tanto, al Gobierno de los Estados Unidos, suspender la Ley de Ajuste Cubano y la Política de Pies SecosPies Mojados, que ha producido y produce este anómalo y peligroso flujo migratorio. Miles de seres humanos, como consecuencia de esa Ley y Política, ponen en riesgo su vida, y se impone igualmente, condiciones y demandas insostenibles a los Gobiernos y Pueblos donde la migración irregular cubana transita ("Nicaragua demanda a Estados Unidos suspender la Ley", 2015).

El texto presidencial afirmaba que el Gobierno de Reconciliación y Unidad Nacional de Nicaragua también se adhería "al justo y digno reclamo del Gobierno de Cuba, de proceder a negociaciones para establecer una migración legal, segura y ordenada, que garantice la vida y los derechos de los ciudadanos cubanos, que recorren estas riesgosas rutas" ("Nicaragua demanda a Estados Unidos suspender la Ley", 2015). 
Llama la atención que unos días después de haber comenzado la crisis, el 19 y 20 de noviembre de 2015, el ministro de Relaciones Exteriores de Cuba, Bruno Rodríguez Parrilla, realizara dos visitas de trabajo a Ecuador y Nicaragua, en las que se reunió con los jefes de Estado de ambas naciones para intercambiar opiniones sobre asuntos de interés bilateral y regional, entre ellos, el tema migratorio ("Realizó canciller cubano visita”, 2015). La nota de prensa no ofrecía detalles de lo tratado en los encuentros. Por su parte, el vicecónsul cubano Abel Cubillas (2017) indicó que no tenía permiso para ofrecer información sobre la crisis migratoria de 2015, más allá de la brindada oficialmente por los medios de comunicación de Cuba en ese momento; mientras, el ministro consejero de la embajada de Nicaragua en Ciudad de México, Juan Carlos Gutiérrez Madrigal, aunque aceptó que se le enviara el cuestionario, nunca respondió a las preguntas.

En cuanto a la comunidad internacional, debido a las relaciones bilaterales entre Cuba y Estados Unidos a lo largo de los años y a la importancia que ha tenido el tema de la migración para ambos países, la crisis ocurrida en Centroamérica no pasó desapercibida. Varios medios de comunicación, los gobiernos de la región y personalidades como el papa Francisco, se pronunciaron por una pronta solución de la situación.

La presión ejercida llevaría a los dos países a sentarse a la mesa y dialogar. Casi un año después, en enero de 2017, Barack Obama, a pocos días de terminar su mandato, eliminó la Política de Pies Secos-Pies Mojados y el Programa de Permisos para Profesionales Médicos Cubanos, pues ambas estaban sujetas a discreción presidencial, a diferencia de la Ley de Ajuste Cubano de 1966, la cual solo puede ser abolida por el Congreso de esa nación.

El Departamento de Seguridad Nacional eliminará la política denominada "wet food-dry food" (Pies Secos-Pies Mojados) que fue creada hace más de veinte años y diseñada para una era diferente. Con efecto inmediato, los ciudadanos de Cuba que intenten entrar a los Estados Unidos ilegalmente y que no cualifiquen para auxilio humanitario serán sujetos a ser devueltos a Cuba [...] El Departamento de Seguridad Nacional también ha puesto fin al Programa de Parole de Médicos Cubanos (Obama, 2017).

Esta decisión fue bien recibida por el gobierno de Raúl Castro, quien vio cómo se hacía realidad su reclamo tras varias décadas. En esa misma fecha, ambos países firmaron un acuerdo en el que expresaron su compromiso de poner en práctica distintas acciones para lograr una migración segura, legal y ordenada entre los dos Estados.

Con la adopción de esta Declaración Conjunta en el día de hoy se elimina un detonante de crisis migratoria. [...] se pone fin a una política de doble rasero discriminatoria hacia los emigrantes de otros países y se promueve una cooperación de beneficio mutuo para la región, no sólo en el área migratoria (Vidal citada en Concepción y Doimeadios, 2017).

De esta manera, Washington se comprometió a otorgar un total de 20000 visas anuales a los cubanos (tal y como lo hizo durante los acuerdos de 1984 y 1994) y prevenir y procesar el tráfico y la trata de personas; mientras La Habana aceptó recibir a 2746 ciudadanos que migraron por el Mariel en los ochenta y fueron considerados inelegibles para permanecer en territorio estadunidense (Vidal citada en Concepción y Doimeadios, 2017). 
Asimismo, acordaron que las autoridades de las dos naciones continuarían reuniéndose de manera periódica, como lo venían haciendo desde mediados de los noventa, para evaluar la marcha de los acuerdos tomados.

La Figura 2 muestra la cantidad de cubanos que obtuvieron la residencia permanente en Estados Unidos desde 2010 y hasta 2017. Con base en la Ley de Ajuste Cubano, que establece el término de un año y un día para que los cubanos, después de haber ingresado al territorio, puedan optar por la residencia permanente, podemos observar que entre los que la obtuvieron en 2016 y 2017 se encuentran los migrantes que formaron parte de la crisis migratoria de 2015, tras el cierre de la frontera nicaraguense.

Figura 2: Cubanos que obtuvieron la residencia permanente en Estados Unidos (año fiscal 2010-2017)

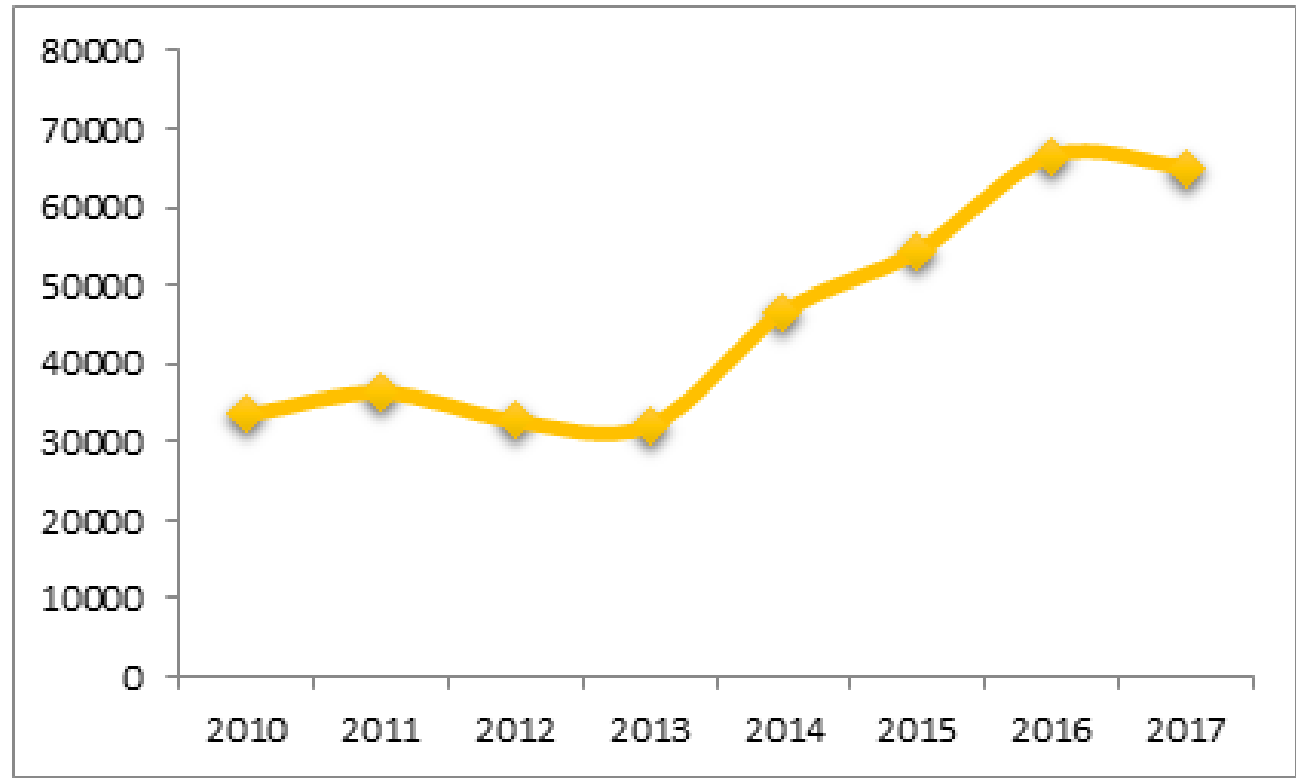

Fuente: Elaboración propia a partir de Yearbooks of Immigration Statistics (Homeland Security, s.f.).

El Departamento de Estado de Estados Unidos (citado en Arias, 2018) indicó que hasta el mes de septiembre de 2017 solamente 2057 cubanos habían llegado sin visa a ese país, la mayoría de ellos procedente de México. Añadía también que desde la firma de la Declaración se había reducido el flujo de la migración indocumentada proveniente de Cuba en $64 \%$ con respecto del año fiscal anterior; mientras el número de migrantes interceptados en altamar había disminuido en $71 \%$.

La Jefatura de Tropas Guardafronteras tiene registrado que tras la entrada en vigor del acuerdo solo se produjeron 60 hechos con 666 participantes, lo que representa una disminución del $94 \%$ de los hechos y del $92 \%$ de los participantes, respecto al año 2016 [...] Del total, solo 24 salidas se dirigieron a territorio estadounidense con 190 participantes, que fueron interceptados por Guardacostas de Estados Unidos y devueltos a Cuba (Arias, 2018). 
Los datos también indican que, desde la firma del convenio, fueron enviados 600 migrantes irregulares desde la nación norteamericana y 1930 provenientes de otros países, entre ellos México y Bahamas. Por su parte, Cuba había recibido hasta el 12 de enero de 2018 a 78 ciudadanos considerados excluibles por la administración estadunidense, quienes habían sustituido a un número similar de los incluidos originalmente en la lista de los "marielitos" (Arias, 2018), personas que migraron en los ochenta por El Mariel y que, en su mayoría, poseían antecedentes penales. ${ }^{17}$

En este sentido, vemos cómo la crisis de migrantes cubanos en Centroamérica a inicios de 2015 permitió justificar, unos meses después, la adopción de cambios importantes en el área migratoria con el fin de seguir delimitando el flujo proveniente de Cuba rumbo a Estados Unidos. Esta crisis fue uno de los motivos que llevó a que el 12 de enero de 2017, el entonces presidente Barack Obama eliminara la política de Pies Secos-Pies Mojados y el Programa de Permisos para Profesionales Médicos Cubanos.

En este proceso de confrontación-acercamiento entre ambos Estados volvió a ocurrir lo que otras veces había pasado: después de cada gran éxodo migratorio cubano se han dado pasos importantes para limitar la migración indocumentada a Estados Unidos, solo que, en esta ocasión, un tercer país, Nicaragua, desempeñó un papel decisivo para la consecución de tal fin.

\section{Nuevas tendencias de la migración cubana}

¿Qué ha pasado con la migración cubana tras la llegada de Donald Trump al poder? ¿Continúa siendo Estados Unidos el principal país receptor de los migrantes de la isla? Son preguntas que se imponen para futuros análisis. Por el momento se puede decir que el actual presidente estadunidense no ha mostrado interés en volver a poner en vigor alguna medida parecida a la Política de Pies Secos-Pies Mojados o al Programa de Permisos para Profesionales Médicos Cubanos.

El discurso antiinmigrante y xenófobo que el actual mandatario esgrimió desde la campaña por la presidencia, las múltiples leyes que ha establecido para restringir la entrada de migrantes a territorio norteamericano, entre ellas la eliminación de la Acción Diferida para los Llegados en la Infancia (DACA), así como los crecientes vínculos establecidos con parte de la comunidad cubano-americana asentada en Miami, un lobby importante dentro de la política doméstica estadunidense, demuestran que continuar avanzando en el área migratoria con Cuba no se encuentra entre los principales objetivos a implementar por Donald Trump en los próximos años.

Sí se puede decir que las reuniones desarrolladas semestralmente entre los dos gobiernos para analizar temas migratorios, entre ellos la trata y tráfico de personas, y que datan de finales de la década de los noventa, continuarán, pues han tenido resultados favorables a lo largo de los años, como lo demostró la cita mantenida entre los dos gobiernos a comienzos de diciembre de 2017.

\footnotetext{
${ }^{17}$ Para Duany (citado en Barbero, 2015), la imagen de los que abandonaron el país por El Mariel ha sido negativa, pues se les identificó como la escoria de la sociedad cubana. Según Aja, Arboleya, Gómez, Quijano y Hernández (2011, p. 93), 60\% de los que salieron del país eran estudiantes, jubilados y amas de casa y $23 \%$ se encontraba en edad laboral y sin trabajo. Del total de personas, $40 \%$ tenía antecedentes penales por robo, hurto y delitos contra la propiedad; $10 \%$ por violar el normal desarrollo de las relaciones sexuales; y solo $5 \%$ por delitos contra la seguridad del Estado.
} 
Por su parte, los trámites para viajar de manera legal a Estados Unidos sufrieron un retroceso con la llegada de Trump al poder, cuando la administración norteamericana retiró a gran parte de los diplomáticos de la embajada en La Habana debido a acusaciones de ataques sónicos contra ellos. De esta manera, quienes pretendan inmigrar actualmente de manera definitiva a la nación norteña deberán ir a Guyana para pedir la visa estadunidense ${ }^{18}{ }^{18}$ los demás trámites migratorios se podrán realizar en cualquier consulado fuera de Cuba. A esto se suma la reciente decisión estadunidense, tomada en marzo de 2019, de modificar las visas B-2 de entradas múltiples con una vigencia de cinco años, a visas de una sola entrada y por un periodo máximo de estancia de tres meses (Tabla 2).

Tabla 2: Cantidad de cubanos sin documentos presentados en los puestos fronterizos de Estados Unidos con México por año fiscal

\begin{tabular}{|c|c|c|c|c|c|c|}
\hline $\begin{array}{l}\text { Puestos fronterizos } \\
\text { de Estados Unidos }\end{array}$ & AF 2014 & AF 2015 & AF2016 & AF2017 & AF2018 & $\begin{array}{c}\text { AF2019 } \\
\text { (febrero) }\end{array}$ \\
\hline El Paso & 415 & 685 & 5018 & 340 & 394 & 2673 \\
\hline Laredo & 15333 & 26181 & 34658 & 14275 & 6533 & 3445 \\
\hline San Diego & 1229 & 1555 & 1589 & 600 & 131 & 77 \\
\hline Tucson & 132 & 221 & 258 & 168 & 21 & 94 \\
\hline Total frontera sur & 17109 & 28642 & 41523 & 15383 & 7079 & 6289 \\
\hline
\end{tabular}

Fuente: U.S. Customs and Border Protection (СBP, 2019).

Entre tanto, la migración cubana indocumentada de tránsito por Centroamérica, tras la derogación de ambas políticas el 12 de enero de 2017, mostró una notable reducción en la región. Muchos cubanos se quedaron varados en los territorios por los que se encontraban pasando cuando Barack Obama dio la noticia, mientras otros han sido devueltos a Cuba, como se puede apreciar en el caso de México (Figura 3).

En este sentido, llama la atención la reciente decisión del gobierno de Daniel Ortega de volver a otorgar desde finales de 2018 y principios de 2019 oficios de tránsito para cruzar el país por un costo de 150 dólares, así como el aumento de las visas de turistas expedidas a cubanos para ingresar a ese país, según declaraciones de migrantes recientes que se encuentran actualmente en México, tras hacer el recorrido de manera indocumentada desde Panamá o la propia Nicaragua (Jorge Lahera, 2019; Laura Valdés, 2019).

En relación con las rutas, empieza a cobrar fuerza también una que ya no tiene como centro a la región centroamericana y México, sino a Guyana, Brasil y Bolivia y como destino final Chile o Uruguay.

\footnotetext{
${ }^{18}$ Desde la fecha de aplicación de esta medida y hasta el 31 de marzo de 2018 los cubanos que querían inmigrar a Estados Unidos debían viajar a Colombia para solicitar la visa a Estados Unidos.
} 
Figura 3: Número de cubanos irregulares en México. Año 2018

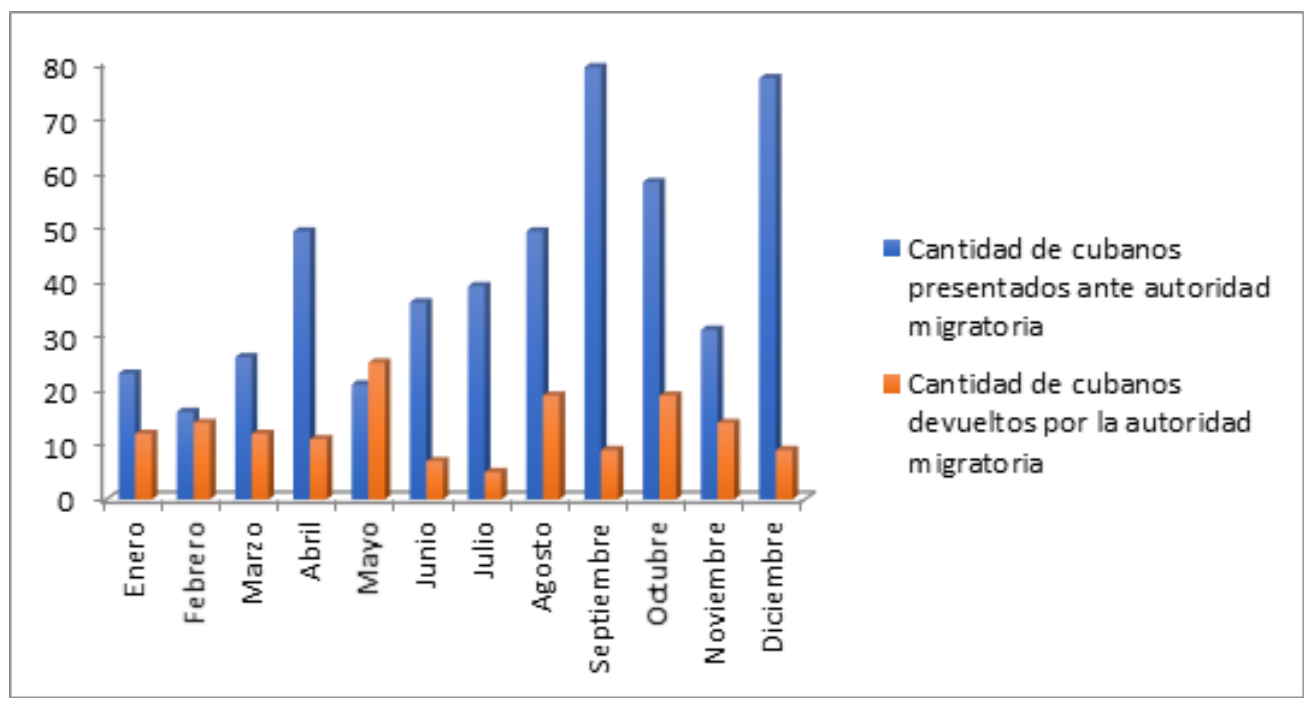

Fuente: Elaboración propia a partir de Boletines estadísticos (Secretaría de Gobernación, 2018).

\section{Conclusiones}

La migración irregular de cubanos a Estados Unidos ha sido utilizada a lo largo de los años por los dos países como un instrumento para generar cambios en las políticas relativas al área migratoria. Después de cada gran éxodo, los dos Estados se han sentado a dialogar y han llegado a acuerdos que contribuyeron, durante el periodo que permanecieron vigentes, a disminuir el flujo indocumentado y a aumentar el legal. La crisis de migrantes en Centroamérica en 2015 no fue la excepción. Casi un año después de que ocurriera, la administración estadunidense derogó parte de las leyes que beneficiaban a los cubanos en esa nación, al eliminar el 12 de enero de 2017 la Política de Pies Secos-Pies Mojados y el Programa de Permisos para Profesionales Médicos Cubanos. Ese mismo día firmó con Cuba una Declaración Conjunta sobre el tema.

Tomando como base lo anterior, el presente artículo ofreció la siguiente hipótesis: que la crisis de migrantes cubanos ocurrida en 2015 fue una política concertada entre La Habana y Managua para presionar a Estados Unidos a dar pasos en el área. La amistad entre el gobierno cubano y el sandinista desde hace décadas fue aprovechada por Cuba para detonar la crisis migratoria, dado que ambos países eran conscientes del incremento del número de cubanos que transitaban por la región (MINREx, 2015).

El cierre de la frontera por tiempo indefinido implicaría un paulatino incremento de los cubanos que llegarían a territorio costarricense con el propósito de seguir trasladándose hacia Estados Unidos, lo cual en corto plazo agotaría las capacidades institucionales costarricenses para continuar brindándoles atención a estos migrantes. Los conflictos limítrofes entre las administraciones de San José y Managua, incluso al interior del sıcA, también contribuirían a que la situación alcanzara una mayor repercusión y visibilización a escala internacional.

Lo demás fue un efecto dominó. Las naciones involucradas comenzaron a exigir la resolución de la crisis, empezando por el gobierno nicaraguense, y, con ella, la actuación de Estados Unidos para que eliminara una de las causas del problema: las leyes que 
durante décadas han beneficiado a los cubanos que llegan a territorio estadunidense, independientemente de la manera en la que lo hagan. La inclusión de varios actores, debido a las implicaciones regionales que la misma tuvo, contribuyó no solo a la resolución del conflicto, sino también a crear el clima ideal para las medidas venideras.

Quienes sí intervienen en la discusión política y en el cambio de ciertas acciones fueron los países centroamericanos, incluyendo a Ecuador y Colombia. Los países andinos, Centroamérica y México sí entran en una discusión sobre el tema y qué hacer sobre el mismo (Ernesto Rodríguez, 2017).

Menos de un año después de solucionarse la crisis de los cubanos indocumentados en Centroamérica, Barack Obama, a pocos días de concluir su mandato como presidente de Estados Unidos, anunció la derogación de la Política de Pies SecosPies Mojados y el Programa de Permisos para Profesionales Médicos Cubanos. De esta manera, las medidas anunciadas el 12 de enero de 2017 constituyeron otro paso dentro del proceso de restablecimiento de relaciones entre Cuba y Estados Unidos, iniciado el 17-D. A partir de esa fecha, la migración indocumentada en tránsito por el continente comenzó a disminuir, pues los cubanos que intenten entrar a territorio estadunidense sin tener la documentación requerida deberán ser tratados como el resto de los migrantes irregulares de América Latina.

\section{Referencias}

Aja, A. (2002). La emigración cubana. Balance en el siglo xx. La Habana, Cuba: Centro de Estudios de Migraciones Internacionales.

Aja, A. (2009) . Al cruzar las fronteras. La Habana, Cuba: Centro de Estudios Demográficos de la Universidad de La Habana.

Aja, A. (2010). Los Estados Unidos-Cuba. Emigración y relaciones bilaterales. Temas, (62-63), 113- 123.

Aja, A. (2017). La perspectiva migratoria en 2017: ¿cambio de reglas? Temas, 20-25.

Aja, A., Arboleya, J., Gómez, A., Quijano, M. M. y Hernández, R. (2011). El Mariel treinta años después. Temas, (68), 80-93.

Anguiano, M. E. y Machado, L. (2015). Emigración cubana a Estados Unidos en un ambiente de restablecimiento de relaciones diplomáticas. Migraciones Internacionales, 8(2), 259- 267.

Arias, F. (2018). Resultados y desafíos de las relaciones migratorias entre Cuba y Estados Unidos. Granma. Recuperado de http://www.granma.cu/ cuba/2018-01-12/resultados-y-desafios-de-las-relaciones-migratorias-entre-cuba-y-ee-uu-12-01-2018-02-01-47

Ávila, G. (2015). La odisea por el sueño americano. Granma. Recuperado de http:// www.granma.cu/mundo/2015-11-19/la-odisea-por-el-sueno-americano

Barberia, L. G. (2010). Cuba, su emigración y las relaciones con los Estados Unidos. Temas, (62-63), 103-112. Recuperado de https://www.academia.edu/2944985/ Cuba_su_emigraci\%C3\%B3n_y_las_relaciones_con_los_Estados_Unidos

Barbero, L. (2015). 35 años del gran éxodo del Mariel. El País. Recuperado de https:/ / elpais.com/internacional/2015/09/13/actualidad/1442113548_063090.html 
Brandoli, J. (2015). El naufragio de los balseros a pie. El Mundo. Recuperado de http:/ / www.elmundo.es/internacional/2015/11/19/564cc5d946163f36188b4653. html

Bravo, J. (2015a). Crisis humanitaria de cubanos en Centroamérica tiene orígenes políticos. Diario Las Américas. Recuperado de http:/ /www.diariolasamericas.com/ america-latina/crisis-humanitaria-cubanos-centroamerica-tiene-origenes-politicos-n3462845

Bravo, J. (2015b). Nicaragua y Costa Rica tenían una práctica de deportación de cubanos. La Prensa. Recuperado de https://www.laprensa.com.ni/2015/11/19/ nacionales/1939533-nicaragua-y-costa-rica-tenian-una-practica-de-deportacion-de-cubanos

Brismat, N. (2011). La política migratoria cubana: Génesis, evolución y efectos en el proceso migratorio insular. En B. Bernal (Coord.), Cuba hoy i Perspectivas de cambio? Ciudad de México (pp. 149-179). México: Biblioteca Jurídica Virtual, Instituto de Investigaciones Jurídicas-unAM.

CBP. (2019). Southwest Border Inadmissibles by Field Office Fiscal Year 2019. Washington D. C., Estados Unidos.

Céspedes, L. y Fariñas, L. (2015). Cuba envejece: ¿éxito o problema? (I). Granma. Recuperado de http://www.granma.cu/cuba/2015-05-10/cuba-envejece-exito-o-problema-i

Compañera Rosario Murillo en Multinoticias. (2018). El 19 Digital. Recuperado de https://www.el19digital.com/articulos/ver/titulo:82191-companera-rosario-murillo-en-multinoticias-3-de-octubre-del-2018

Concepción, J. y Doimeadios, D. (2017). Josefina Vidal: se elimina un detonante de la crisis migratoria entre Cuba y Estados Unidos. Cubadebate. Recuperado de http://www.cubadebate.cu/noticias/2017/01/12/josefina-vidal-hoy-se-elimina-un-detonante-de-crisis-migratoria-entre-cuba-y-euu/\#.Woor1KjwbIU

Curbelo, C. (2015). Curbelo Introduces the Cuban Immigrant Work Opportunity Act [Archivo de video]. Recuperado de https://www.youtube.com/watch?v=dWHA0Fxn7ew\&feature $=$ youtu.be

De Armas, A. (2015). Cuba y el cuarto éxodo [Archivo de video]. Martí Noticias. Recuperado de https://www.radiotelevisionmarti.com/a/cuarto-exodo-masivo-desdecuba-a-ee-uu/112065.html

De Urrutia, L. (1997). Aproximación a un análisis del proceso migratorio cubano. Papers, 52, 49-56.

Departamento de Seguridad Nacional de Estados Unidos. (s.f.). Programa de Permisos para Profesionales Médicos Cubanos (CMPP). Recuperado de https://www.uscis.gov/es/programas-humanitarios/permiso-humanitario/programa-de-permisos-para-profesionales-medicos-cubanos-cmpp

Domínguez, E. (1990). La política soviética y cubana hacia Nicaragua: 1979-1989. Papers, 35, 95- 115.

Flor, M. J. (2015). Migración cubana en Ecuador: una mirada al proceso de descalificación (Tesina de especialización). Facultad Latinoamericana de Ciencias Sociales, sede Ecuador, Quito, Ecuador.

Hernández, Y. (2011). La emigración de Cuba hacia los Estados Unidos en la historia. Novedades en Población, 7(14), 297-318. 
Homeland Security (DHS) (s.f.). Yearbook of Immigration Statistics. Recuperado de https://www.dhs.gov/immigration-statistics/yearbook

Homenaje del gobierno de Nicaragua a creadora del método pedagógico "Yo, sí puedo". (2018). Ministerio de Relaciones Exteriores de Cuba, La Habana, Cuba. Recuperado de http://misiones.minrex.gob.cu/es/articulo/homenaje-del-gobierno-de-nicaragua-creadora-del-metodo-pedagogico-yo-si-puedo

González, R. A. (2018). La Ley de Ajuste Cubano después de la Guerra Fría. Novedades en Población, 14(27), 1-13.

LeoGrande, W. M. y Kornbluh, P. (2015). Diplomacia encubierta con Cuba. Historia de las negociaciones secretas entre Washington y La Habana (Sandra Sepúlveda Amor, trad.). México: Fondo de Cultura Económica.

López, H. (2008). Los cubanos. En H. López (Coord.), La demografía hispánica en el suelo norteamericano. Enciclopedia del español en los Estados Unidos. Madrid, España: Instituto Cervantes.

Martínez, M. (1996). Los balseros cubanos, un estudio a partir de las salidas ilegales. La Habana, Cuba: Editorial de Ciencias Sociales.

Ministerio de Relaciones Exteriores de Cuba (MinRex). (2015). Declaración del Ministerio de Relaciones Exteriores de la República de Cuba. La Habana, Cuba.

Ministerio de Salud Pública. (2018). Anuario Estadístico de Salud de la República de Cuba 2017. La Habana, Cuba: Ministerio de Salud Pública.

Miroff, N. (2015). The Other Migrant Crisis: Cubans are Streaming North in Large Numbers. The Washington Post. Recuperado de https://www.washingtonpost. $\mathrm{com} /$ world/the_americas/the-other-migrant-crisis-cubans-are-streaming-north-in-large-numbers/2015/12/05/3160772e-992f-11e5-aca6-1ae3be6f06d2_ story.html?utm_term $=.0$ ba88cbafcec

Moreno, G. (2018). Migración indocumentada en Centroamérica: políticas migratorias de los países de tránsito hacia los cubanos tras el restablecimiento de relaciones entre Cuba y Estados Unidos (Tesis de maestría). El Colegio de México, México.

Nicaragua demanda a Estados Unidos suspender la Ley de Ajuste Cubano y la Política de Pies Secos-Pies Mojados (2015). El 19 Digital. Recuperado de https://www. el19digital.com/articulos/ver/titulo:36969-nicaragua-demanda-a-eeuu-suspender-la-ley-de-ajuste-cubano-y-la-politica-de-pies-secospies-mojados

Obama, B. (2017). Declaración del presidente sobre la Política de Inmigración Cubana. Embajada de Estados Unidos en Cuba, Washington D.C., Estados Unidos.

Oficina Nacional de Estadística e Información de la República de Cuba [ONEI] (2016). Salario medio en cifras. Cuba 2016. La Habana, Cuba.

Oficina Nacional de Estadística e Información de la República de Cuba (ONEI). (2017). Principales términos demográficos 2017. Anuario Demográfico de Cuba. La Habana, Cuba: ONEI.

Oficina Nacional de Estadística e Información de la República de Cuba y Centro de Estudios de Población y Desarrollo (ONEI-CEPDE). (2016). Migraciones a nivel de estratos y asentamientos: resultados principales en la Encuesta Nacional de Migraciones, ENMIG. La Habana, Cuba: ONEI-CEPDE.

Organización Internacional para las Migraciones (OIM). (2006). Glosario sobre migración. Ginebra, Suiza: OIM. 
Por la voluntad común de la nación cubana (2012). Granma. Recuperado de http:// www.granma.cu/granmad/2012/10/16/nacional/artic12.html

Ramírez, E. (2016). ¿Qué entender por una normalización de las relaciones entre Cuba y Estados Unidos? Granma. Recuperado de http://www.granma.cu/ cuba/2016-11-01/que-entender-por-una-normalizacion-de-las-relaciones-entre-cuba-y-estados-unidos-01-11-2016-21-11-39

Realizó canciller cubano visita de trabajo a Ecuador y Nicaragua (2015). Cubadebate. Recuperado de http://www.cubadebate.cu/noticias/2015/11/21/realizo-canciller-cubano-visita-de-trabajo-a-ecuador-y-nicaragua/\#.Wguu2tQwhkg

Reed, G. (2015). Reflexiones sobre la migración cubana: entrevista con el Dr. Antonio Aja, director del Centro de Estudios Demográficos de la Universidad de La Habana. MEDICC Review Selecciones, 17(4), 15-18.

Rodríguez, E. (1997). El flujo emigratorio cubano, 1985-1996. Balances y perspectivas. Revista Ciencias Sociales, 3, 37-81.

Secretaría de Gobernación (2018). Boletines estadísticos. Recuperado de http://www. politicamigratoria.gob.mx/es_mx/SEGOB/Boletines_Estadisticos

Villareal, R. y Silva, J. (2015). Nicaragua expulsó a 1,917 cubanos. La Prensa. Recuperado de https://www.laprensa.com.ni/2015/11/16/nacionales/1937515-nicaragua-expulso-a-1917-cubanos-nicaragua-expulso-a-1917-cubanos

\section{Material legislativo}

Decreto-Ley Número 302 modificativo de la Ley Número 1312, "Ley de Migración" de 20 de septiembre de 1976. (2012). Gaceta Oficial de la República de Cuba, 16 de octubre de 2012. La Habana, Cuba, Ministerio de Justicia.

Ley de Migración (2011). Diario Oficial de la Federación, 25 de mayo de 2011. Congreso General de los Estados Unidos Mexicanos. Ciudad de México, México.

Ley No 1313 de 20 de septiembre de 1976 Ley de Extranjería (1976). Gaceta Oficial de la República de Cuba, La Habana, Cuba: Ministerio de Justicia.

Memorando de entendimiento entre el Gobierno de la República de Cuba y el Gobierno de los Estados Unidos Mexicanos para garantizar un flujo migratorio legal, ordenado y seguro entre ambos países (2008). Senado de la República Mexicana, México.

\section{Entrevistas}

Ernesto Rodríguez Chávez (21 de junio de 2017). Entrevista realizada por Gleicys Moreno. Ciudad de México, México.

Jorge Lahera (seudónimo). (24 de febrero de 2019). Entrevista realizada por Gleicys Moreno. Ciudad de México.

Laura Valdés (seudónimo). (24 de febrero de 2019). Entrevista realizada por Gleicys Moreno. Ciudad de México, México.

Luis Yoel Lamorú. (4 de marzo de 2017). Entrevista realizada por Gleicys Moreno vía Skype. 
Vicecónsul cubano Abel Cubillas Díaz. (4 de julio de 2017). Entrevista realizada por Gleicys Moreno. Ciudad de México, México.

Gleicys Moreno Rodríguez

Cubana-nicaragüense. Maestra en ciencia política por el Colegio de México (Colmex), con estudios en relaciones internacionales por la Universidad Autónoma de Madrid, España. Asistente de Investigación en el Centro de Investigación en Ciencias e Información Geoespacial (CentroGeo). Proyecto: Región Transfronteriza MéxicoGuatemala. Dimensión Regional y Bases para su Desarrollo Integral. Líneas de investigación: migración, políticas públicas y derechos humanos. 